\title{
Supercritical pyrolysis and coking of JP-10 in regenerative cooling channels
}

\author{
Yu Pan ${ }^{\mathrm{b}}$, Haocui Zhang ${ }^{\mathrm{a}}$, Chunyu Zhang ${ }^{\mathrm{a}}$, Hongyan Wang ${ }^{\mathrm{a}}$, Kai Jing ${ }^{\mathrm{c}}$, Linmin Wang ${ }^{\mathrm{c}}$, \\ Xiangwen Zhanga, Guozhu Liu ${ }^{a^{*}}$
}

a. School of Chemical Engineering and Technology, Tianjin University, Tianjin, 300072, China.

b. School of Aerospace Engineering, National University of Defense Technology, Changsha, Hunan, 410073, China

c. Binhai Industrial Institute of Tianjin University, Tianjin University, Tianjin, 300072, China.

Due to the heat lost into environment, there existed a difference between the electrically resistive heating power and the heat absorbed by the feeding fuel. To obtain the real value of absorbed heat, a method was proposed as below: an empty channel was electrically heated, then the tube temperature reached a supposed value and maintained consistently. At this temperature, the heating power was supposed to be equal to the heat lost into environment. By repeating this procedure with different temperature, a regression line was obtained, shown as Fig S1.

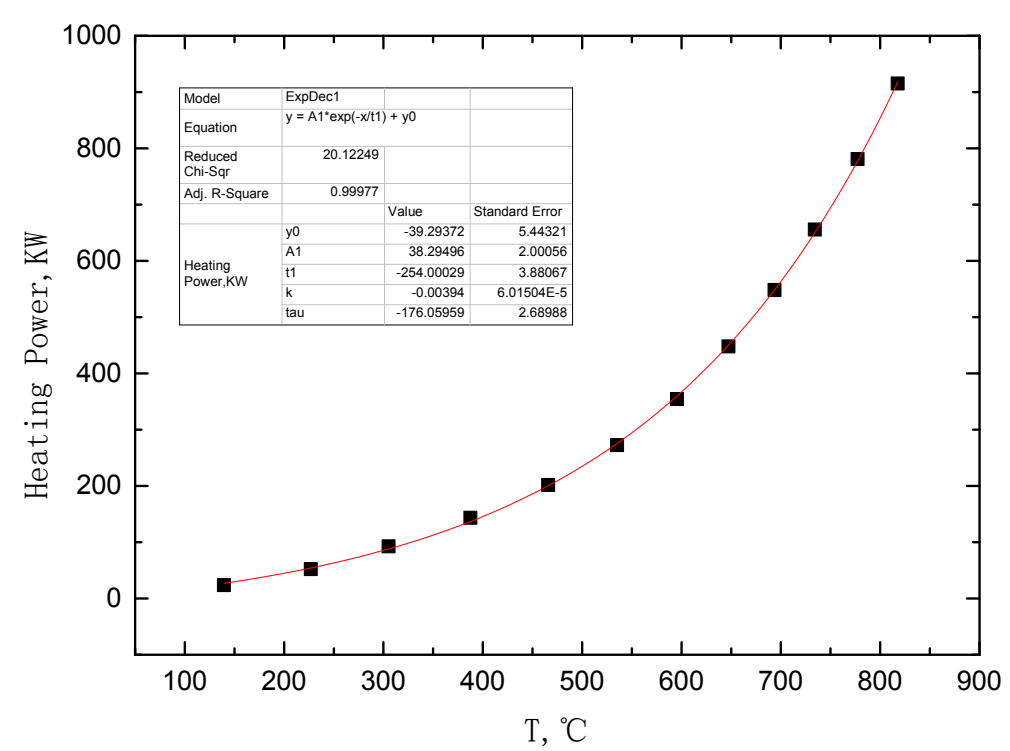

Fig. S1 Heat loss of the electrically heated tube without fuel flow through as a function of wall temperature 

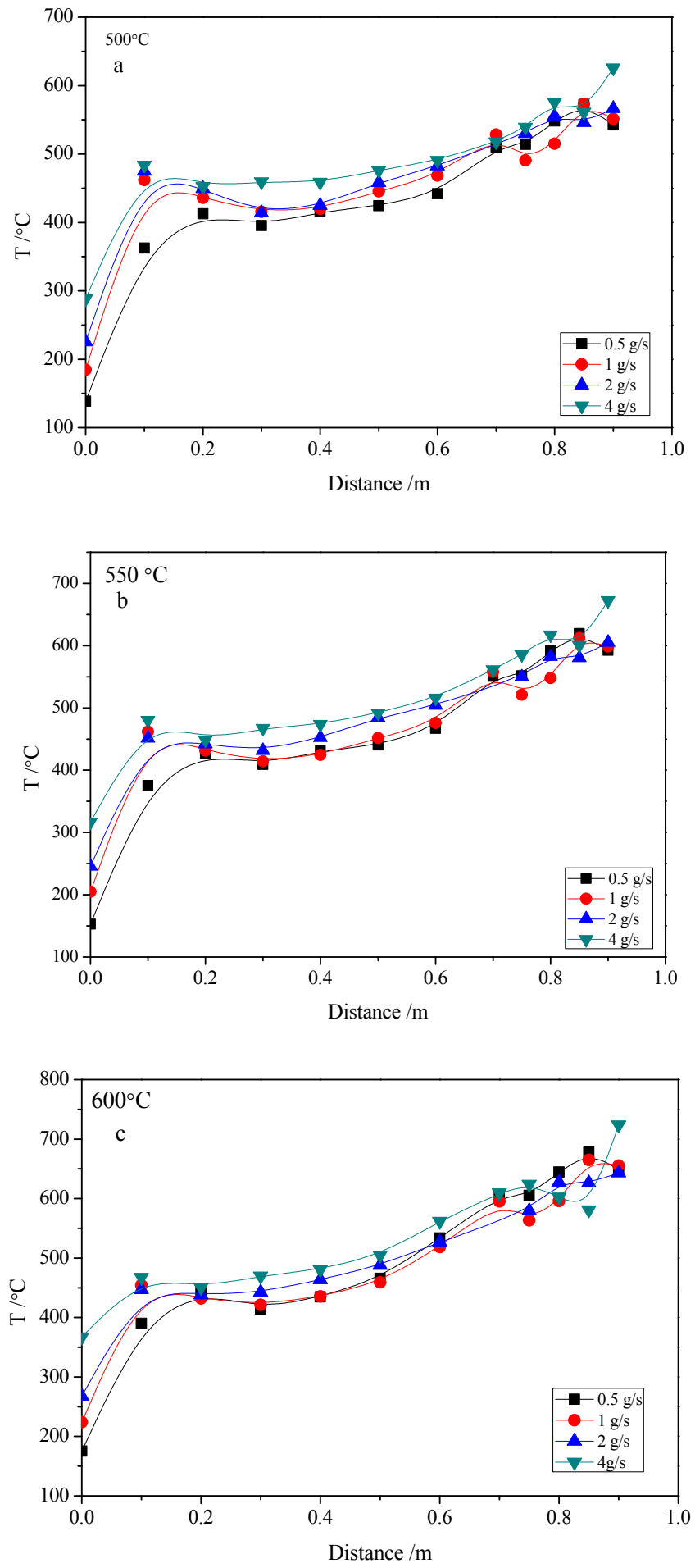

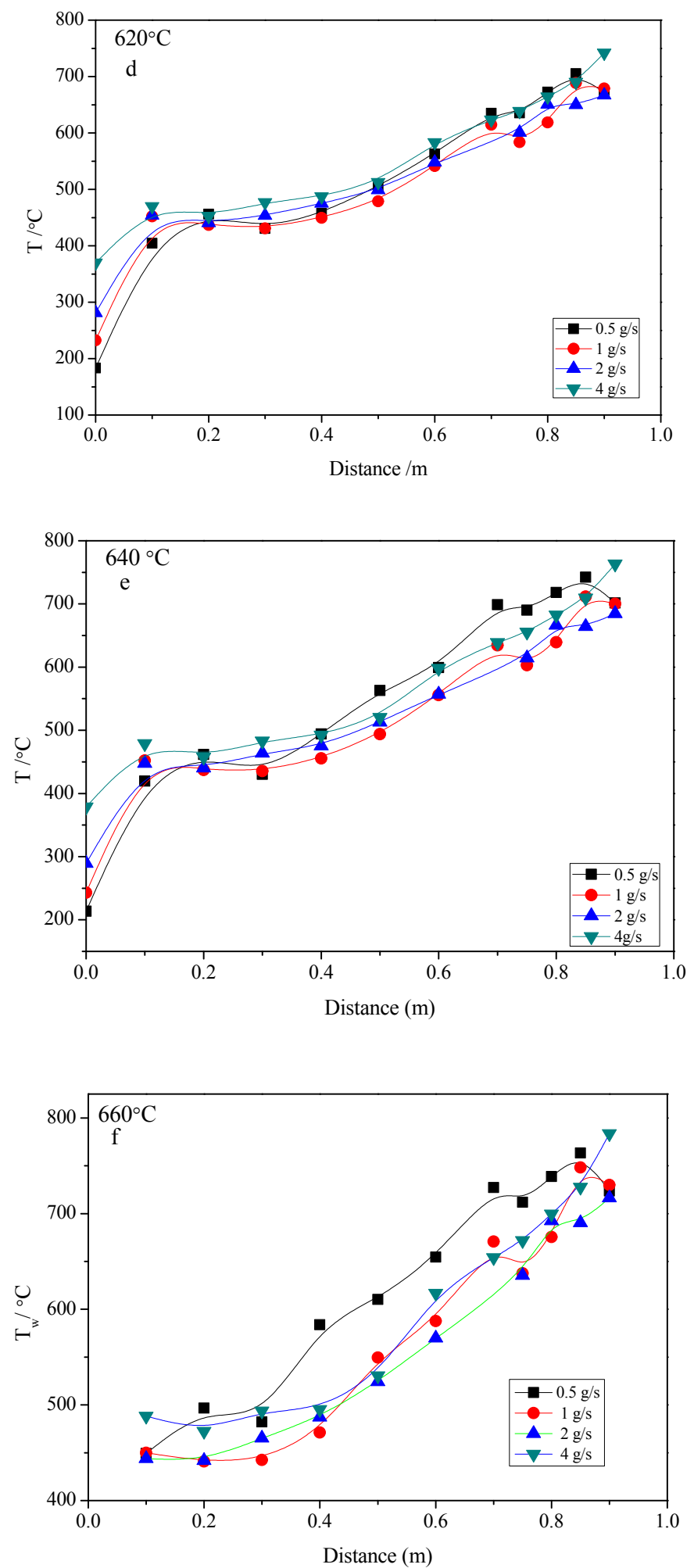


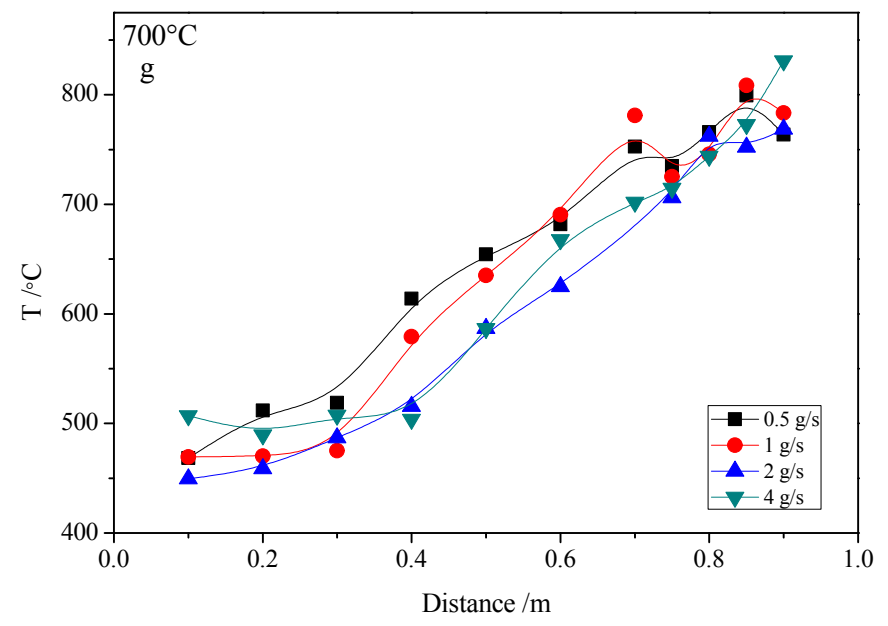

Fig. S2 Wall temperature along the cooling channel with the fuel outlet temperature of (a) 500, (b)550, (c) $600{ }^{\circ} \mathrm{C},(\mathrm{d}) 620^{\circ} \mathrm{C},(\mathrm{f}) 640{ }^{\circ} \mathrm{C}$, (g) $700{ }^{\circ} \mathrm{C}$ at different flow rate.
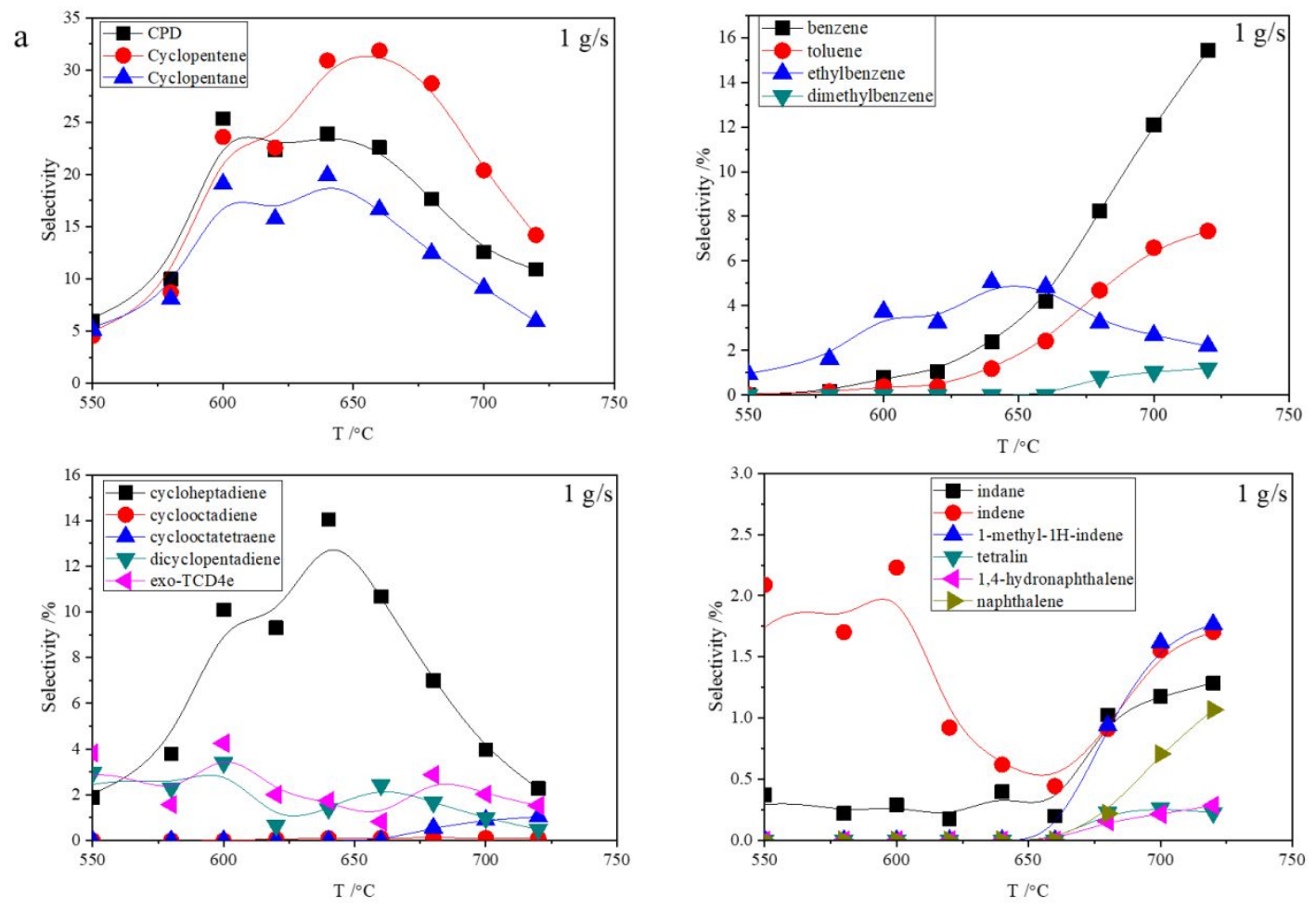
b
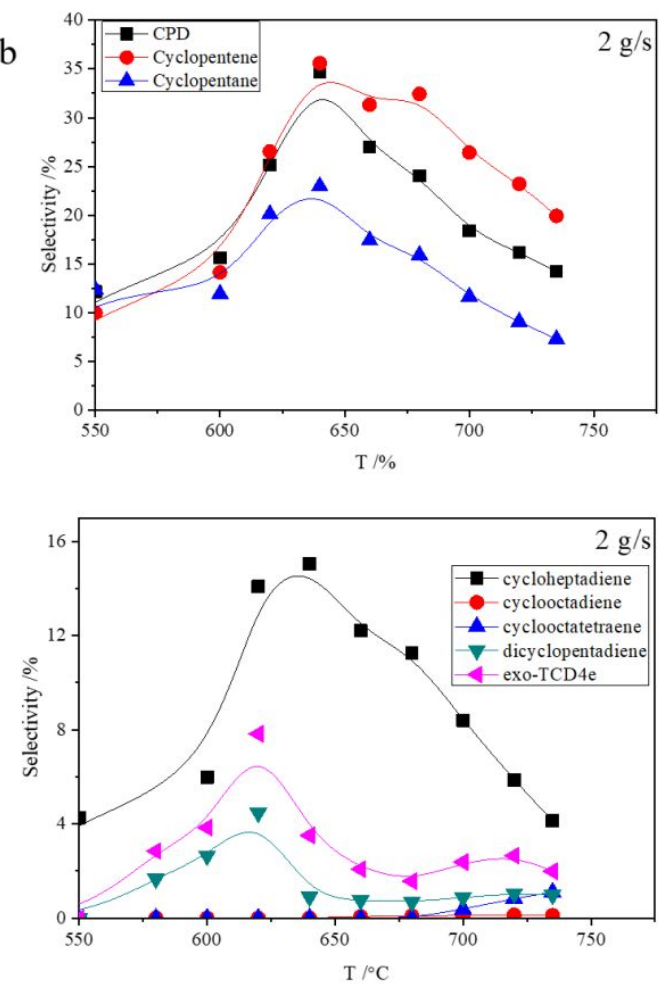

c
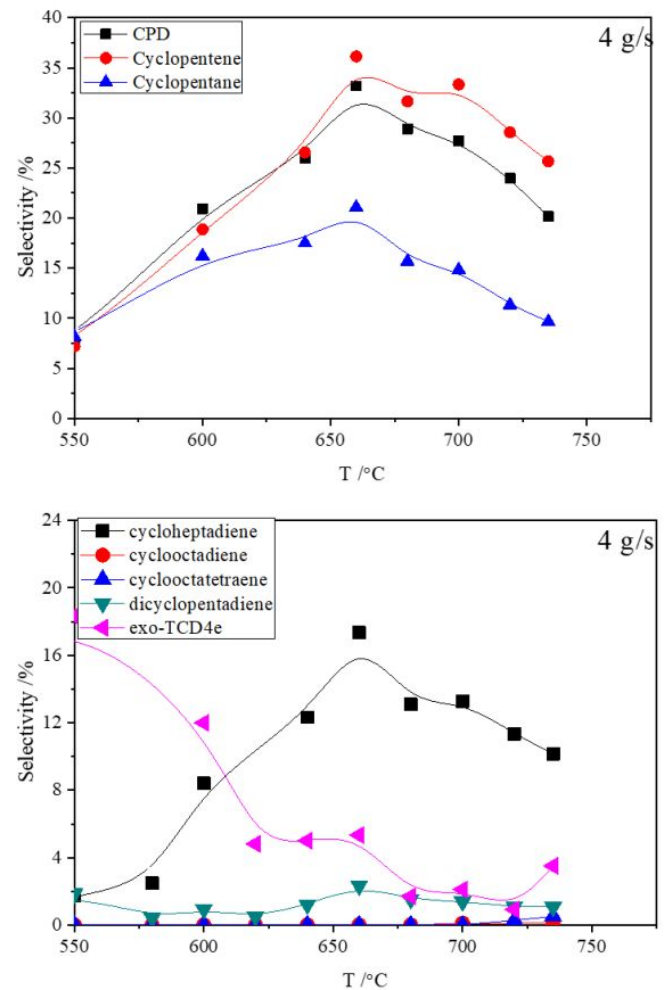
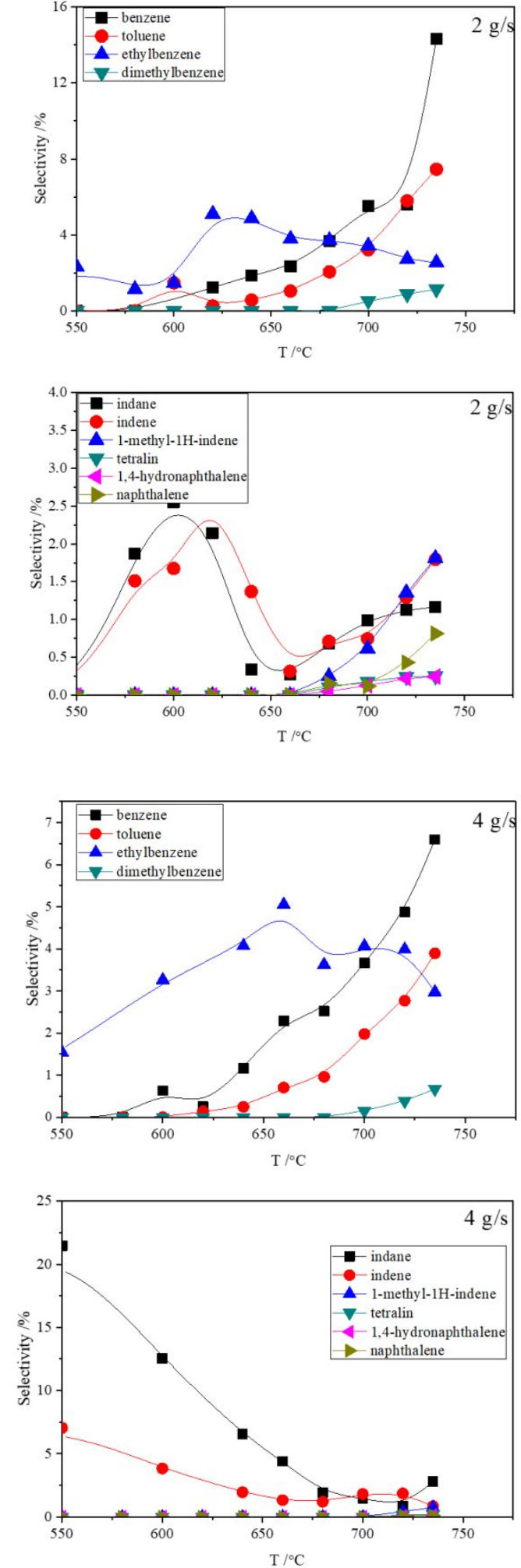

Fig. S3 The content of components in liquid products as a function of outlet bulk fuel temperature at different feeding rate. $(4.5 \mathrm{MPa})$ 